\title{
Insights into the Biology, Infections and Laboratory Diagnosis of Chlamydia
}

\author{
H.N. Madhavan, J. Malathi and R. Bagyalakshmi \\ Larsen and Toubro Microbiology Research Centre, Kamal Nayan Bajaj Institute for \\ Research in Vision and Ophthalmology, Vision Research Foundation, \\ College Road, Sankara Nethralaya, Chennai \\ India
}

\section{Introduction}

Chlamydia are Gram negative obligate intracellular bacteria of eukaryotic cells and have a unique developmental cycle consisting of formation of infectious particle called elementary body and non-infectious particle called reticulate body. They are included in the order Chlamydiales and the order Chlamydiales belongs to the class Chlamydiae, phylum Chlamydiae, domain bacteria. The genus Chlamydia consists of important species C. muridarum, (affects only mice and hamsters) C. suis (affects only swine) and C. trachomatis (a human pathogen). Chlamydia are Gram-negative obligate intracellular eubacteria. Originally, they were taxonomically categorized into their own order Chlamydiales, with one family, Chlamydiaceae, and a single genus, Chlamydia. ${ }^{1}$ The genus included four species: C. trachomatis, C. psittaci,C. pneumoniae and C. pecorum .In 1999, it was proposed by Everett et al 2 that Chlamydia should be divided in two genera, Chlamydia and Chlamydophila, containing altogether nine species (Table 1) in addition to the five new species and three new families (Parachlamydiaceae,

\begin{tabular}{|c|c|c|}
\hline Species & Host & Route of entry \\
\hline \multicolumn{3}{|c|}{ CHLAMYDIA } \\
\hline Chlamydia trachomatis & Humans & $\begin{array}{l}\text { Pharyngeal, ocular, genital, } \\
\text { rectal }\end{array}$ \\
\hline Chlamydia suis & Pigs & Pharyngeal \\
\hline Chlamydia muridarum & Mouse, hamster & Pharyngeal, genital \\
\hline \multicolumn{3}{|c|}{ CHLAMYDOPHILA } \\
\hline Chlamydophila abortus & Mammals & Oral, genital \\
\hline Chlamydophila caviae & Guinea pig & $\begin{array}{l}\text { Pharyngeal, ocular, genital, } \\
\text { urethral }\end{array}$ \\
\hline Chlamydophila felis & Cats & Pharyngeal, ocular, genital \\
\hline Chlamydophila pecorum & Mammals & Oral \\
\hline Chlamydophila pneumoniae & $\begin{array}{l}\text { Humans ,frog, koala, } \\
\text { horse }\end{array}$ & Pharyngeal, ocular \\
\hline Chlamydophila psittaci & Birds & Pharyngeal, ocular, genital \\
\hline
\end{tabular}

Table 1. The family Chlamydiaceae as proposed by Everett et al (1999) 
Simniaceae and Waddliaceae).The molecular characteristics distinguishing Chlamydia and Chlamydiales is shown in Table 2. However, the proposal to change the taxonomic nomenclature for the Chlamyadiaceae family has not been generally accepted in the field. 3 Two of the species, C. trachomatis and C. pneumoniae, are common pathogens in humans, whereas the other species occur mainly in animals.

\begin{tabular}{|c|c|c|c|}
\hline Genus & $\begin{array}{c}\text { Approximate } \\
\text { Genome Size } \\
\text { (million DNA base } \\
\text { pairs) }\end{array}$ & $\begin{array}{c}\text { Detectable } \\
\text { Glycogen }\end{array}$ & $\begin{array}{c}\text { Number of } \\
\text { Ribosomal } \\
\text { Operons }\end{array}$ \\
\hline Chlamydophila & 1.2 & Absent & 1 \\
\hline Chlamydia & 1.0 & Present & 2 \\
\hline
\end{tabular}

Table 2. Molecular Criteria Distinguishing Chlamydiaceae

\section{Life cycle}

Chlamydia trachomatis exhibits an affinity for the epithelial cells of mucous membranes such as those found on the surfaces of the cervix, urethra, rectum, nasopharynx and conjunctiva, and enter these cells by a phagocytic process. ${ }^{4}$ Within infected cells, Chlamydiae occur in intra cytoplasmic vesicles, or inclusion bodies. Within these inclusion bodies, morphological development takes place and two distinct particles are observed: a small, dense infective particle, the elementary body which is transformed in the host cell into the larger less dense form, the reticulate body. These non-infective but metabolically active reticulate bodies synthesize proteins and their own DNA and RNA, then replicate by binary fission to form micro colonies within the inclusion bodies. Between 18-24 hours post infection, the reticulate bodies divide and then ultimately some of the reticulate bodies reorganize into large numbers of elementary bodies. Between 48 and 72 hours post infection, the host cells ruptures releasing elementary bodies which can infect new host cells. ${ }^{5}$ The life cycle of $C$. trachomatis is shown in Figure 1. The species of Chalmydia causing infections is shown in Table 3.

\begin{tabular}{|c|c|c|}
\hline Species of Chlamydia & Serovars & Infection caused by the serovars \\
\hline \multirow{3}{*}{ Chlamydia trachomatis } & $\mathrm{A}, \mathrm{B}, \mathrm{Ba}, \mathrm{C}$ & Blinding trachoma \\
\cline { 2 - 3 } & $\mathrm{D}-\mathrm{K}$ & $\begin{array}{c}\text { Genital infections and infant pneumonia, } \\
\text { Inclusion conjunctivitis }\end{array}$ \\
\cline { 2 - 3 } & L1,L2,L3 & Lymphogranuloma venereum (LGV) \\
\hline Chlamyophila psitacii & - & Psittacosis \\
\hline Chlamydophila pneumoniae & - & Acute respiratory disease \\
\hline
\end{tabular}

Table 3. Chalmydia causing different infections 


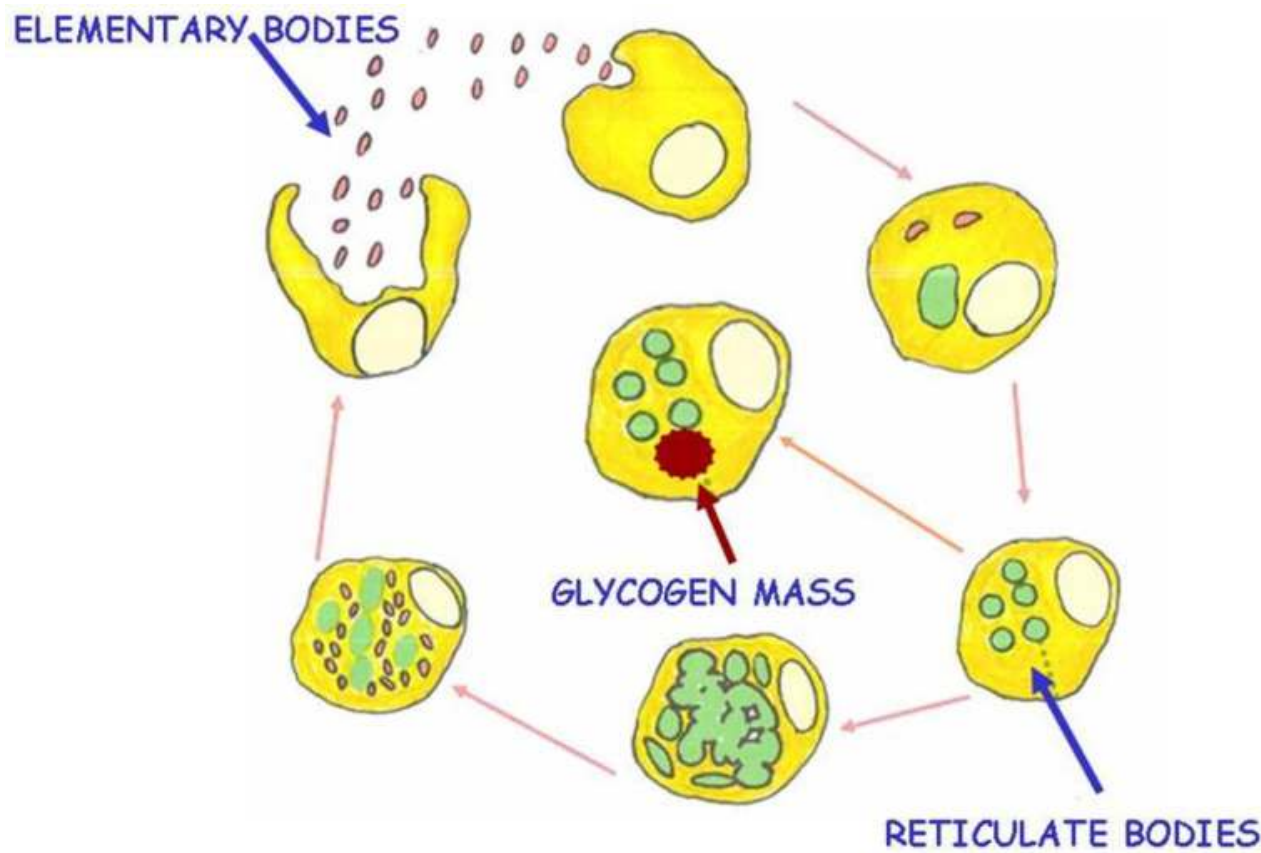

Fig. 1. Life Cycle of Chlamydia

\section{Clinical manifestations}

C. trachomatis causes trachoma, infant pneumonia, LGV and nongonococcal urethritis.

Although most infections caused by $C$. trachomatis in women are asymptomatic, clinical manifestations include cervicitis, urethritis, endometritis, Pelvic Inflammatory Disease (PID) or abscess of the Bartholin glands. ${ }^{6}$ Although the initial site of infection is usually the cervix, the urethra and rectum may also be infected. ${ }^{7}$ The prevalence of $C$. trachomatis infection in pregnant women ranges from 2 to $35 \% .8$ Pregnant women with chlamydial infections are at increased risk for adverse outcomes of pregnancy, and postpartum PID.

C. trachomatis is the most common cause of neonatal conjunctivitis and pneumonia in early infancy.${ }^{9}$ Fifteen to $25 \%$ of treated infants who were exposed at birth develop conjunctivitis, and 3 to $16 \%$ develop pneumonia. Symptoms of conjunctivitis usually develop within 2 weeks of delivery, and if the infection is untreated, chlamydial pneumonia can develop at 4 to 17 weeks after delivery .10 These conditions are occasionally difficult to treat, and prolonged hospitalization may be necessary . Infants with chlamydial pneumonia are at increased risk for later pulmonary dysfunction and possibly for chronic respiratory disease ${ }^{11}$

Trachoma. Endemic trachoma is a chronic disease caused by repeated infections of the conjunctiva and cornea by $C$. trachomatis. Trachoma is probably the most common cause of preventable blindness worldwide. Epidemiologic studies of trachoma in developing countries have shown that this disease is most often due to infection by $C$. trachomatis serotypes A to C. Scarring of the conjunctiva with resultant trauma to the cornea appears to 
be due to repeated exposure to the chlamydial agent, which is transmitted primarily by nonsexual mechanisms. The ability to identify $C$. trachomatis from the conjunctivae of trachoma patients may vary greatly depending on the duration and clinical stage of the disease. ${ }^{12}$

Lymphogranuloma venereum (LGV) LGV is a systemic disease caused by $C$. trachomatis serovars L1 to L3. The LGV serovars of C.trachomatis are more invasive than other genital serovars, resulting in infection of the epithelial layers and underlying soft tissue. ${ }^{13}$ The primary symptom is a painless genital ulcer or papule. The most common manifestation of the secondary stage of LGV in men, and the reason most men seek treatment, is inflammation and swelling of the inguinal lymph nodes. Women tend to be less symptomatic at this stage: only 20 to $30 \%$ of women present with inguinal lymphadenopathy and approximately one-third of women without proctocolitis present with lower abdominal and back pain. ${ }^{14}$ The secondary stage of infection is characterized by systemic symptoms including fever, malaise, chills, anorexia, myalgia, and arthralgia .15 Untreated infections can lead to late complications including ulceration and hypertrophy of the genitalia, arthritis, and fistula formation involving the rectum, bladder, vagina, or vulva ${ }^{14}$

Nongonococcal urethritis. C. trachomatis serotypes D to K are the organisms most frequently associated with nongonococcal urethritis in men As many as one-third of men who harbor urethral Chlamydia may be asymptomatic In 1 to $2 \%$ of chlamydial urethral infections, infection can evolve to epididymitis. C. trachomatis is the most commonly isolated microorganism in young heterosexual men with epididymitis in whom there is no structural abnormality of the genitourinary disease. C. trachomatis infects the endocervix of women and may cause mucopurulent cervicitis. ${ }^{8}$

This infection frequently spreads to the urethra and urinary bladder and may result in the "acute urethral syndrome"of abacteriuric pyuria .12

Pneumonia Pneumonia and bronchitis are the most frequently recognized illnesses associated with C. pneumoniae, although asymptomatic infection or unrecognized, mildly symptomatic illnesses are the most common result of infection. In a series of studies $10 \%$ of cases of pneumonia and approximately $5 \%$ of bronchitis and sinusitis cases in adults have been attributed to the organism ${ }^{16}$.No set of symptoms or signs is unique to pulmonary infections with C. pneumoniae; however, several characteristics of the clinical presentation may help distinguish it from other causes .17 A subacute onset is common. Pharyngitis, sometimes with hoarseness, is often present early in the course of the illness. There may be a biphasic pattern to the illness, with resolution of pharyngitis prior to development of a more typical bronchitis or pneumonia syndrome. Cough is very common and is often prolonged. ${ }^{18,19}$

Psittacosis. Reiter's classic description of respiratory disease associated with avian exposure (ornithosis, formerly "psittacosis") was the first modern recognition of C. psittaci disease. Both psittacine and nonpsittacine birds can harbor the infectious agent, and avian C. psittaci strains cause illness in bird handlers and poultry workers. Because of the antigenic diversity of C. psittaci, serologic methods based on detection of antibody responses to genus-specific antigens of chlamydiae are used for the presumptive diagnosis of ornithosis. Although C. psittaci can be isolated in cell culture or by animal 
inoculation with clinical specimens, the low sensitivity of these methods and the biohazard of C. psittaci in the laboratory have made serologic diagnosis the indicated laboratory method for diagnosis of ornithosis.

Mammalian. In spite of the broad range of non human hosts, zoonotic C. psittaci strains other than avian strains have infrequently been reported to cause human infection. A few cases of human infection resulting in abortion have been reported following infection by ovine C. psittaci strains . Rare cases of infective endocarditis presumed to be due to C. psittaci from avian and nonavian sources have also been reported. C. psittaci strains TWAR infections a novel group of chlamydial organisms has been associated with acute respiratory disease in humans. The acronym TWAR is derived from Taiwan-acute respiratory, the designations given to the first University of Washington studies that produced these strains. TWAR organisms have morphologic, antigenic, and developmental similarities to C. psittaci and are not inhibited in vitro by sulfonamides. Molecular studies of deoxyribonucleic acid relatedness suggest that TWAR agents are genetically homogeneous and differ from both $C$ .psittaci and C. trachomatis. 20

\section{Epidemiology}

Although C. trachomatis infection did not become a fully reportable disease in the United States until 1996, it is known to be the most common bacterial sexually transmitted disease (STD). The actual incidence of chlamydial infection is not yet known due to lack of reporting in all 50 states up to 1996; however, national trends have been estimated by using data from states that reported cases prior to 1996, sentinel surveillance, surveys, and models based on proxies of infection .21,22 Worldwide, it is estimated that there are more than 50 million new cases of $C$. trachomatis infection annually. ${ }^{23}$ Although the major impact of disease caused by C. trachomatis is on the female reproductive tract, this agent also causes infections in men and children. ${ }^{24}$ The prevalence of $C$. trachomatis infection in sexually active adolescent women, the population considered most at risk, generally exceeds $10 \%$, and in some adolescent and STD clinic populations of women, the prevalence can reach $40 \%$. ${ }^{25}$ The prevalence of C.trachomatis infection ranges from 4 to $10 \%$ in asymptomatic men and from 15 to $20 \%$ in men attending STD clinics. ${ }^{26,} 27$ Chlamydial infections in newborns occur as a result of perinatal exposure; approximately $65 \%$ of babies born from infected mothers become infected during vaginal delivery. ${ }^{28}$

\subsection{Clinical sequelae of $C$. trachomatis infections in infants}

C. trachomatis is the most common cause of neonatal conjunctivitis and one of the most common causes of pneumonia in early infancy. Prophylactic treatment of the eyes with silver nitrate does not prevent chlamydial infection; 15 to $25 \%$ of treated infants who were exposed at birth develop conjunctivitis, and 3 to 16\% develop pneumonia. ${ }^{29}$ Symptoms of conjunctivitis usually develop within 2 weeks of delivery and if the infection is untreated, chlamydial pneumonia can develop at 4 to 17 weeks after delivery. These conditions are occasionally difficult to treat, and prolonged hospitalization may be necessary. Infants with chlamydial pneumonia are at increased risk to develop pulmonary dysfunction and possibly chronic respiratory disease. ${ }^{30}$ 


\subsection{Clinical sequelae of $C$. trachomatis infections in men}

Among heterosexual men, chlamydial infections are usually urethral and up to $50 \%$ are asymptomatic ${ }^{31}$. When symptoms do occur, usually 1 to 3 weeks following exposure, they are indistinguishable from those of gonorrhea (urethral discharge and/or pyuria). However, compared with gonococcal urethritis, chlamydial urethritis is more likely to be asymptomatic. In older men, epididymitis is more often due to other etiologies associated with urinary tract abnormalities or instrumentation rather than sexually transmitted origins. ${ }^{32}$ Unilateral scrotal pain is the primary symptom, and common clinical signs of this infection include scrotal swelling, tenderness, and fever. If urethral symptoms are also present, a sexually transmitted bacterial etiology is likely..$^{33}$

\subsection{Reitter's syndrome}

Reitter's syndrome is caused by Chlamydia trachomatis The manifestations of reactive arthritis include the following triad of symptoms: an inflammatory arthritis of large joints including commonly the knee and the back (due to involvement of the sacroiliac joint), inflammation of the eyes in the form of conjunctivitis or uveitis, and urethritis in men or cervicitis in women. Patients can also present with mucocutaneous lesions, as well as psoriasis-like skin lesions such as circinate balanitis, and keratoderma blennorrhagica. Not all affected persons have all the manifestations, and the formal definition of the disease is the occurrence of otherwise unexplained non-infectious inflammatory arthritis combined with urethritis in men, or cervicitis in women. ${ }^{34}$ Symptoms generally appear within 1-3 weeks but can range from 4 to 35 days from the onset of the inciting episode of the disease. The classical presentation is that the first symptom experienced is a urinary symptom such as burning pain on urination (dysuria) or an increased frequency of urination. Other urogenital problems may arise such as prostatitis in men and cervicitis, salpingitis and/or vulvovaginitis in women. ${ }^{35}$ The arthritis that follows usually affects the large joints such as the knees causing pain and swelling with relative sparing of small joints such as the wrist and hand. Eye involvement occurs in about $50 \%$ of men with urogenital reactive arthritis and about $75 \%$ of men with enteric reactive arthritis. Conjunctivitis and uveitis can include redness of the eyes, eye pain and irritation, or blurred vision. ${ }^{36}$

\subsection{Laboratory diagnosis of chlamydial infections}

Specimens used for detecting Chlamydiae must be handled cautiously following universal precautions. Handling of specimens for the detection of C. psittaci requires type III containment facility. The organism is air-borne and is highly virulent. ${ }^{20}$ The most common anatomic site used to obtain specimens for the isolation of $C$. trachomatis from women is the endocervix, which is sampled with a swab (endocervix, Dacron and calcium alginate) or cytologic brush. The swab should be inserted into the cervical os past the squamocolumnar junction, about 1 to $2 \mathrm{~cm}$ deep, rotated for 15 to $30 \mathrm{~s}$, and removed without touching the vaginal mucosa. ${ }^{13}$ The transport medium may contain fetal calf serum up to $10 \%$ to preserve the viability of the organisms. The transport media may contain gentamycin or vancomycin, nystatin/ amphotericin B at a concentration of 10 microgram / $\mathrm{ml}$ to prevent the growth of other bacteria and fungi respectively while transport. Specimen upon receipt in the laboratory should be processed as early as possible. In case of delay the specimen can be stored for a maximum period of 48 hours in the refrigerator. If further delay is expected 
the specimen should be stored at $-70^{\circ} \mathrm{C}$ until further processed. 37,38 The earlier methods used for the direct detection include iodine staining which stains the glycogen present in the cell lines. Giemsa staining is applied to detect the inclusion bodies of the organism. Later mononclonal antibodies raised against the major outer membrane protein gene of the organism tagged with a Fluorecein Iso thiocyanate (FITC) dye was widely used for the rapid detection of the agent from direct clinical specimens. ${ }^{39}$

\subsection{Cultivation}

Until recently, culture was considered the gold standard for detection of Chlamydia in specimens because it has a specificity that approaches $100 \%$. The usual cell lines in use are HeLa 229, L434 mouse fibroblasts or McCoy cells in the case of C. trachomatis and C. psittaci; Buffalo green monkey kidney cells for C. psittaci and C. pecorum, HeLa or Hep2 cells for C. pneumoniae. The disadvantages of using culture as a gold standard include its relative insensitivity compared with DNA amplification techniques. ${ }^{40}$ With the exception of 'fast growing' strains like the LGV biovar of $C$. trachomatis, it was usually necessary to assist the process of infection by centrifugation of the clinical material onto monolayers of the appropriate cells in tissue culture. Growth of the organisms was also facilitated by the use of anti-metabolites directed against the host cell (cycloheximide; emetine or mitomycin C) or, for the C. trachomatis TRIC: Trcahoma Inclusion conjunctivitis biovar, by the use of charged anionic polymers such as Poly - L - lysine or DEAE dextran. Compounds like polyethylene glycol or high energy glucose 6 phosphate also aided the growth of some chlamydiae. ${ }^{41}$

\subsection{Rapid shell vial technique for cultivation}

Modified culture technique where the cells are grown over cover slips placed inside a glass shell vial is used for the rapid cultivation of Chlamydia. Here the cells are grown over the

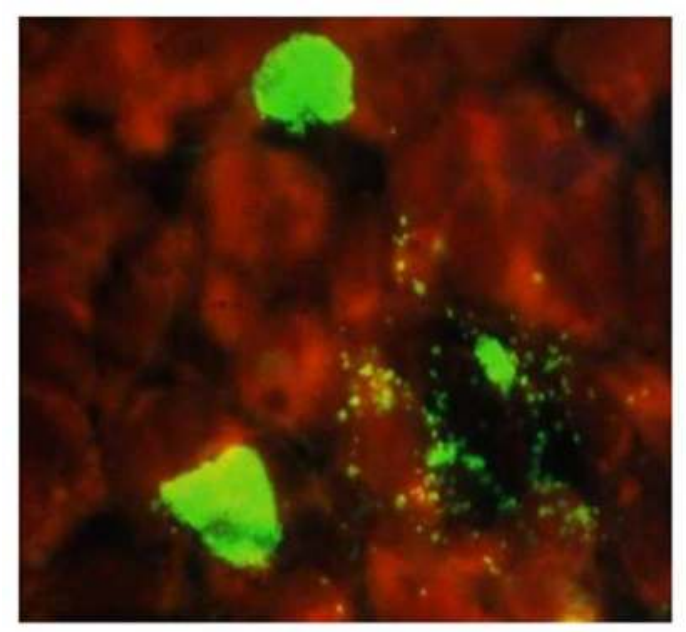

Fig. 2. Immunofluorescence staining showing Reticulate and Elementary bodies of Chlamydia trachomatis isolated from a case of ophthalmia neonatorum in McCoy cell culture $(40 \mathrm{X})$ 
cover slips and treated with cycloheximide $(1$ microgram $/ \mathrm{ml})$ containing medium for 24 hours. 42 After the medium is aspirated out 200 micro liters of clinical specimen is added and the culture is centrifuged centrifuged at $3000 \mathrm{rpm}$ for 1 hour. At the end of 1 hour, Dulbecco's minium essential medium with $10 \%$ fetal calf serum and 1-3 microgram cycloheximide is added and incubated at 37 oC $\left(10 \% \mathrm{CO}_{2}\right.$ atmosphere $)$ for $48-72$ hours. At the end of incubation period the medium is aspirated out, the cover slip is fixed and stained with the antisera (Figure 2). This method is rapid and more sensitive in isolation of Chlamyida. ${ }^{43}$

Since susceptibility of a cell line is an important factor for cultivation of $C$. trachomatis, Malathi et al ${ }^{44}$ have compared McCoy, HeLa, BHK-21, HEp-2, Vero and A549 cell lines for growth characteristics of $C$. trachomatis. These were inoculated with 150 infection-forming units (IFU) of C. trachomatis A, B, Ba and C serovars. Growth was graded according to the number of IFUs per microscopic field (100X). A549-cell line was not susceptible to infection by any of the serovars. The growth of $C$. trachomatis was good to very good in McCoy and HeLa cell lines. Vero, BHK-21 and HEp-2 cell lines varied considerably in the susceptibility to infection. ${ }^{44}$

\subsection{Polymerase chain reaction (PCR) and Ligase chain reaction (LCR)}

Plasmids of Chlamydia are known to exist in 7 copy numbers. Due to the rapidity, increased sensitivity and specificity PCR, LCR methods have widely replaced the conventional culture methods. ${ }^{42,43}$ The major target for amplification based tests against $C$. trachomatis are generally multiple-copy gene products, such as the cryptic chlamydial plasmid (Figure 3 ) or ribosomal RNA, Major outer membrane protein gene. Starting with a multiple copy gene offers a clear starting advantage with respect to sensitivity. The application of initial nucleic acid amplification based tests had increased the clinical sensitivity of detection of chlamydial DNA in clinical samples. ${ }^{22,45}$ The major advantage of nucleic acid based amplification technique is the combined sensitivity and specificity. Automation is possible and a large volume of sample can be handled at a time. The technique was helpful to establish the etiology of the C. pneumoniae in optic neuritis ${ }^{46}$ where cultivation of the organism was not possible

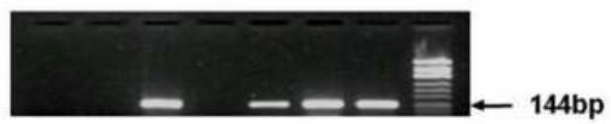

\section{1: Negative control 4: specimen negative for PCR \\ 2: Extraction control $\mathrm{p}$ : positive control: C. trachomatis Ba DNA \\ 3, 5 \& 6 : conjunctival swabs positive for PCR \\ $M:$ PHI X 174 DNA/ Hinf I digest}

Fig. 3. Agarose electrophoretogam showing the MOMP amplified products of $C$. trachomatis from conjunctival swabs 


\section{Screening tests for chlamydia}

C. trachomatis infection is asymptomatic in $80 \%$ of women making diagnosis and detection difficult. Chlamydia has its high prevalence amongst young men and women and more than $13.5 \%$ of women $<25$ years old have lower genital tract infections. 47 Screening women for lower genital tract infection with $C$. trachomatis is important in the prevention of PID, ectopic pregnancy and infertility. ${ }^{48}$ The screening tests available for $C$. trachomatis include nucleic acid based amplification assays, PCR and LCR, gene probe and enzyme immuno assay. The sensitivity and specificity of Chlamydia trachomatis screening tests is provided in Table 4.

\begin{tabular}{|l|l|l|l|}
\hline Test & Sensitivity & Specificity & $\begin{array}{l}\text { Detection limit } \\
\text { (no of organisms) }\end{array}$ \\
\hline NAAT $^{a}$ & $90-95$ & $>99$ & $1-10$ \\
\hline DFA $^{b}$ & $80-85$ & $>99$ & $10-500$ \\
\hline EIA $^{c}$ & $60-85$ & 99 & $500-1000$ \\
\hline DNA Probed & $75-85$ & $>99$ & $500-1000$ \\
\hline Cell culture & $50-85$ & 100 & $5-100$ \\
\hline POCe & $20-55$ & $>90$ & $>10,000$ \\
\hline
\end{tabular}

NOTE:

a DNA based amplicor assay (Roche diagnostic, Basel Switzerland), LCR (Abbott Lab, Abbott Park IL, USA)

${ }^{b}$ DFA Expansion: Direct fluorescence assay - Syva MicroTrak (Syva Co, Palo, Alto, CA, USA)

c EIA - Vidas (BioMerieux, Craporre France)

d DNA probe based hybrid capture assay (QIAGEN, Hilden Germany), Ampliprobe system (Imclone systems, NY, USA) RNA Based (Gen probe San Diego CA, USA)

e Point of care test: Handilab C (Zonda incorporated Dallas TX, USA), Biorapid Chlamydia antigen test (Biokit, Barcelona, Spain) Quick Vue Chlamydia test (Quidel Corporation, San Diego CA, USA)

Table 4. Sensitivity and specificity of Chlamydia trachomatis detection assays and most widely used commercially available tests 49

Screening programmes are promoted to control transmission and prevention of female reproductive tract morbidity caused by genital Chlamydia. Offering an annual screening test to men and women aged under 20 years may be the most cost effective strategy if PID progression is $10 \%$ or higher. Screening is essential to reduce the propagation of the disease. Annual testing is recommended for women at high risk for Chlamydial infection. According to Centre for Disease Control (CDC), the following patients population should be screened for Chlamydia infection.

- Sexually active female adolescents

- Women undergoing induced abortion

- Women attending STD clinic

- Women with mucopurulent cervicitis

- Women with new / multiple sexual partners within 3 months of presentation ${ }^{50}$ 


\subsection{Chlamydial infection in chronic ill patients}

C. pneumoniae infection can cause acute respiratory illnesses (including sinusitis, bronchitis, and pneumonia) that are sometimes associated with wheezing. Little is known about whether acute infection in a previously unexposed, non asthmatic individual can produce persistent wheezing leading to a diagnosis of chronic asthma. Hahn et al 51 conducted a study on 163 primary outpatient adults (average age 43, 45\% male) who had acute wheezing illnesses or chronic asthma to evaluate C. pneumoniae infection by serologic testing. C. pneumoniae infection was diagnosed if the organism was detected one or more times by culture, or if a patient met accepted serologic criteria for acute infection: an IgM antibody titer of 1:16 or greater, a fourfold or greater rise in IgM, IgG or total Ig titer between acute and convalescent sera, or a single IgG or total Ig titer of 1:512 or greater. ${ }^{11}$ Criteria for an acute primary (first exposure) C. pneumoniae infection include the presence of IgM antibody in a titer of 1:16 or greater whereas $\operatorname{IgM}$ is absent in acute secondary infection (re-exposure).In the setting of acute bronchitis or pneumonia, a single IgG titer of 1:512 or greater correlates with organism identification and is also indicative of acute infection.

Acute C. pneumoniae respiratory tract infections in previously unexposed, non asthmatic individuals can result in chronic asthma. Patients previously diagnosed with chronic asthma should be evaluated for possible chronic C. pneumoniae infection.

\subsection{Chlamydial infections in pregnancy}

Prematurity is one of the leading causes of perinatal mortality. Uterine contractions may be induced by cytokines, proteolytic enzymes or prostaglandins released or induced by microorganisms. Some studies 52,53 suggest that maternal C. trachomatis infection in pregnancy is associated with premature delivery. Termination of pregnancy (i.e. induced abortion) is one of the most commonly performed gynecological procedures. Post-abortal PID is a well recognized complication of termination of pregnancy, with its attendant risks of tubal dysfunction and either infertility or subsequent ectopic pregnancy.

\section{Prevention}

Chlamydia prevention programs have been implemented to reduce the burden of reproductive sequelae resulting from chlamydial infection. Because most reproductive complications of Chlamydia occur in females and most infections are asymptomatic, the cornerstone of Chlamydia prevention is screening young females for infection. Nucleic acid amplification tests are the preferred diagnostic tests because of their superior sensitivity, and they can be performed on easily collected specimens, such as urine or vaginal swabs..$^{53}$ Highly efficacious treatment options include single-dose oral azithromycin or a 1-week course of doxycycline. National chlamydia screening recommendations were first released in 1993. Currently, CDC, the U.S. Preventive Services Task Force (USPSTF), and numerous professional medical associations recommend annual chlamydia screening for all sexually active females aged $<25$ years and for females aged $\geq 25$ years if they are at increased risk for infection (e.g., if they have new or multiple sex partners. ${ }^{54}$

C. pneumoniae is difficult to prevent because it is spread by respiratory droplets from other sick people.Because people with this type of pneumonia do not always feel very sick, they 
often continue to attend school, go to work, and go to other public places. They then spread the bacteria in the tiny droplets that are released into the air during coughing. Therefore, this pneumonia is very difficult to prevent and often occurs in outbreaks within communities. ${ }^{20}$ Prevention of $C$. trachomatis pneumonia involves recognizing the symptoms of genital infection in the mother and treating her prior to delivery of her baby. ${ }^{53}$

\subsection{Prognosis of Chlamydia infection}

The 'prognosis' of Chlamydia usually refers to the likely outcome of Chlamydia. The prognosis of Chlamydial infection may include the duration, chances of complications of Chlamydia infection, probable outcomes, prospects for recovery, recovery period for Chlamydia, survival rates, death rates, and other outcome possibilities in the overall prognosis of Chlamydia. Naturally, such forecast issues are by their nature unpredictable

The following are statistics from various sources about deaths related to Chlamydia:

Chlamydia death statistics for various regions worldwide:

- $\quad$ About 1,000 deaths from Chlamydia in Africa 2002

- About 8,000 deaths from Chlamydia in South East Asia 2002

- About 1,000 deaths from Chlamydia in Eastern Mediterranean 200255

- Treated with antibiotics, chlamydial infections can be cured $95 \%$ of the time.

\subsection{Chlamydial infection in children}

Exposure to $C$. trachomatis during delivery can cause ophthalmia neonatorum (conjunctivitis) in neonates or chlamydial pneumonia at one to three months of age.

\subsection{Ophthalmia neonatorum}

Ophthalmia neonatorum usually occurs within five to 12 days of birth but can develop at any time up to one month of age. It may cause swelling in one or both eyes with mucopurulent drainage. Prophylaxis with silver nitrate or antimicrobial ointment, which reduces the risk of gonococcal infection in neonates, does not reduce the risk of chlamydial infection. Testing for chlamydial infection in neonates can be done by culture or nonculture techniques. The eyelid should be everted and the sample obtained from the inner aspect of the eyelid. Sampling the exudates is not adequate because this technique increases the risk of a false-negative test. Ophthalmia neonatorum can be treated with erythromycin base or ethylsuccinate at a dosage of $50 \mathrm{mg}$ per $\mathrm{kg}$ per day orally, divided into four doses per day for 14 days. The cure rate for both options is only 80 percent, so a second course of therapy may be necessary. Topical treatment is ineffective for ophthalmia neonatorum and should not be used even in conjunction with systemic treatment. 53

\subsection{Chlamydial pneumonia}

Acute lower respiratory tract infection (ALRTI) is the major cause of morbidity and mortality in young children world wide.Chlamydia pneumoniae is a common respiratory pathogen which is responsible for about $10 \%$ of community acquired pneumonia (CAP). The best method of microbiological diagnosis at the acute stage of Chlamydial infection is 
undecided, because the organism grows poorly on cell culture. ${ }^{20}$ Testing can be performed on a sample obtained from the nasopharynx. Nonculture techniques may be used, but they are less sensitive and specific for nasopharyngeal specimens than for ocular specimens. If tracheal aspirates or lung biopsies are being collected for pneumonia in infants one to three months of age, the samples should be tested for $C$. trachomatis.

Like ophthalmia neonatorum, pneumonia secondary to $C$. trachomatis is treated with erythromycin base or ethylsuccinate at a dosage of $50 \mathrm{mg}$ per $\mathrm{kg}$ per day orally, divided into four doses per day for 14 days. As with ophthalmic infection, a second course of therapy may be necessary. 53

\section{Advanced research}

\subsection{Polymorphisms associated with ocular and genital isolates of $C$. trachomatis}

Genome sequence of several diverse strains has revealed a remarkable level of genomic synteny suggesting that minor genetic differences determine the pathogen host and tissue specific infection characteristics. To better understand the genetic basis of Chalmydial pathobiologic diversity, Carlson et al ${ }^{56}$ performed a comparative DNA -DNA microarray genomic hybridization and reported with all 15 Chlamydia trachomatis serovariants and reported only a few major genetic differences. An exception was the cytotoxin locus located in the plasticity zone, a region that exhibited significant polymorphisms among serovars. The cytotoxin gene was interrupted by extensive mutants and deletions among different serovars however 3 basic open reading frames (ORF) were discovered that correlated with non invasive genitotropic serovars which possess an intact $\mathrm{N}$ terminal portion of the putative toxin gene. This region contains the UDP Glucose binding domain and the glycosyl transferase domain required for enzymatic activity of Clostridium toxin homologues suggesting a role in urogenital infection/ pathogenesis. ${ }^{57}$

C. trachomatis exists as multiple serovariants that exhibit distinct organo tropism for the eye or urogenital tract. The genome of an oculotropic trachoma isolate (A/HAR-13) was sequenced and compared to the genome of a genitotropic (D/UW-3) isolate. Remarkably, the genomes share $99.6 \%$ identity, supporting the conclusion that a functional tryptophan synthase enzyme and toxin might be the principal virulence factors underlying disease organotropism. Tarp (translocated actin-recruiting phosphoprotein) was identified to have variable numbers of repeat units within the $\mathrm{N}$ and $\mathrm{C}$ portions of the protein. A correlation exists between lymphogranuloma venereum serovars and the number of $\mathrm{N}$-terminal repeats. Single-nucleotide polymorphism (SNP) analysis between the two genomes highlighted the minimal genetic variation. A disproportionate number of SNPs were observed within some members of the polymorphic membrane protein (pmp) autotransporter gene family that corresponded to predicted T-cell epitopes that bind HLA class I and II alleles. These results implicate Pmps as novel immune targets, which could advance future chlamydial vaccine strategies. Lastly, a novel target CTA0934 for PCR diagnostics was discovered that can discriminate between ocular and genital strains. This discovery will enhance epidemiological investigations in nations where both trachoma and chlamydial STD are endemic. The results suggest that Tarp is among the few genes to play a role in adaptations to specific niches in the host. ${ }^{58}$ 


\subsection{Chlamydial L,L - diaminopimelate aminotransferase}

Recent phylogenetic studies have revealed that chlamydia shares a common ancestor with modern plants and retains unusual plant-like traits (both genetically and physiologically). In particular, the enzyme L,L-diaminopimelate aminotransferase, which is related to lysine production in plants, is also linked with the construction of chlamydia's cell wall. The genetic encoding for the enzymes is remarkably similar in plants and chlamydia, demonstrating a close common ancestry. ${ }^{59}$ This unexpected discovery may help scientists develop new treatment avenues: if scientists could find a safe and effective inhibitor of L,Ldiaminopimelate aminotransferase, they might have a highly effective and extremely specific new antibiotic against chlamydia.

\subsection{Emerging Chlamydial infections}

Several Chlamydial like bacteria have recently been identified as potential emerging public threats or pathogenic agents in animals. Parachlamydia acanthamoebae, Parachalmydia naegelerophila and Simkania negerensis have been reported as possible aetiological agents of pneumonia in humans. To define further the possible pathogenetic potential of these Chlamydia like bacteria new diagnostic tools are needed to demonstrate the agent within tissue lesions. ${ }^{60}$ Borel et al 60 have used tissue microarray technology to establish the immuno histochemistry protocols and to determine the specificity of new antisera against various Chlamydia like bacteria for future use on formalin fixed and paraffin embedded tissues. The antisera exhibited strong reactivity against autologous antigen and closely related heterologous antigen but no cross reactivity with distantly related species.

\section{References}

[1] Moulder, J.W., Hatch, J.P., Kuo, C.C., Schachter, J.T. , Storz, J.(1984) Genus Chlamydia. In: Krieg NR \& Holt JG (eds) Bergey's Manual of Systematic Bacteriology, vol 1. Williams \& Wilkins, Baltimore, MD, 729-739.

[2] Everett, K.D., Bush, R.M, Andersen, A.A, (1999) Emended description of the order Chlamydiales, proposal of Parachlamydiaceae fam. nov. and Simkaniaceae fam. nov., each containing one monotypic genus, revised taxonomy of the family Chlamydiaceae, including a new genus and five new species, and standards for the identification of organisms. International Journal of Systematic Bacteriology, 49 (2), 415-440.

[3] Schachter, J., Stephens, R.S., Timms, P., Kuo, C., Bavoil ,P.M., Birkelund, S., Boman, J., Caldwell, H., Campbell, L.A., Chernesky, M., Christiansen, G., Clarke, I.N., Gaydos, C., Grayston, J.T., Hackstadt, T., Hsia, R., Kaltenboeck, B., Leinonnen, M., Ocjius, D., McClarty, G., Orfila, J., Peeling, R., Puolakkainen, M., Quinn, T.C., Rank, R.G,, Raulston, J., Ridgeway, G.L., Saikku, P., Stamm, W.E., Taylor-Robinson, D.T., Wang, S.P. , Wyrick, P.B., (2001) .Radical changes to chlamydial taxonomy are not necessary just yet. International Journal of Systematic Evolutionary Microbiology, 51 (249), 251-243. 
[4] Barbour, A.G., Amano, K., Hackstadt, T., Perry, L., Caldwell, H.D., (1982).Chlamydia trachomatis has penicillin-binding proteins but not detectable muramic acid. Journal of Bacteriology , 151, 420-428.

[5] Fox. A, Rogers. J.C., Gilbart, J., Morgan, S., Davis, C.H., Knight, S. ,Wyrick, P.B.,(1990). Muramic acid is not detectable in Chlamydia psittaci or Chlamydia trachomatis by gas chromatography-mass spectrometry. Infection and Immunity, 58, 835-837.

[6] Stephens, R.S. Chlamydial evolution: a billion years and counting. In: Schachter J et al. (eds) Chlamydial Infections. Proceedings of the Tenth International Symposium on Human Chlamydial Infections. Antalya, Turkey, June 2002, 3-12.

[7] Bleker, O.P., Smalbraak, D.J., Shutte, M.F., (1990) .Bartholin's abscess: the role of Chlamydia trachomatis. Genitourinary. Medicine, 66,24-25.

[8] Dunlop, E.M.C.,Goh,B.T., Darougar, S., Woodland, R., (1985). Triple culture tests for the diagnosis of Chlamydial infection of the female genital tract. Sexually Transmitted. Diseases $12,68-71$.

[9] Sweet, R.L., Landers, D.V., Walker ,C., Schachter, J., (1987). Chlamydia trachomatis infection and pregnancy outcome. American Journal of Obstetetrics and Gynecology, $156,824-833$.

[10] Hammerschlag, M.R., Cummings, C., Roblin, P.M, Williams, T.H, Delkem, I.(1989) Efficacy of neonatal ocular prophylaxis for the prevention of chlamydial and gonococcal conjunctivitis. New England Journal of Medicine, 320,769-772

[11] Claesson, B.A., Trollfors, B., Brolin, I.,Granstrom, M., Henrichsen, J., Jodal, U., Juto,P., Kallings, I., Kanclerski, K.,Lagergard, T.,(1989). Etiology of community-acquired pneumonia in children based on antibody responses to bacterial and viral antigens. Pediatric Infectious Diseases Journal, 8, 856-862.

[12] Saikku,P. Chlamydia pneumoniae - an update on clinical disease. In: Schachter J et al. (eds) Chlamydial Infections. Proceedings of the Tenth International Symposium on Human Chlamydial Infections. Antalya, Turkey, June 2002, 443-453.

[13] Black,C.N., (1997).Current methods of laboratory diagnosis of Chlamydia trachomatis infections. Clinical Microbiology Reviews, 10 (1),160-184

[14] Pearlman, M.D., McNeeley, S.G.,(1992). A review of the microbiology,immunology, and clinical implications of Chlamydia trachomatis infections. Obstetrics Gynecology. Survey, 47, 448-461.

[15] Perine, P.L., Osoba, A.O., (1990). Lymphogranuloma venereum, p 195-204. In K. K. Holmes, P.-A. Mårdh, P. F. Sparling, and P. J. Wiesner (ed.), Sexually transmitted diseases. McGraw Hill Book Co., New York,N.Y.

[16] Grayston, J.T., (1992). Infections caused by Chlamydia pneumoniae strain TWAR. Clinical Infectious Disease,15,757-763.

[17] Grayston, J.T., Aldous, M.B., Easton, A., Wang, S.P., Kuo, C.C., Campbell, L.A., Altman, J., (1993). Evidence that Chlamydia pneumoniae causes pneumonia and bronchitis. Journal of Infectious Diseases; 168,1231-1235.

[18] Grayston, J.T., Kuo, C.C., Wang, S.P., Altman, J, (1986).A new Chlamydia psittaci strain, TWAR, isolated in acute respiratory tract infection.New. England Journal of Medicine 315,161-168. 
[19] Thom, D.H., Grayston, J.T., Wang, S.P., Kuo, C.C., Altman, J., (1990). Chlamydia pneumoniae strain TWAR, Mycoplasma pneumoniae and viral infections in acute respiratory disease in a university student health clinic population. American Journal of Epidemiology , 132, 248-256.

[20] Kuo, C.C., Jackson, L.A, Campbell, L.A, Grayston, J.T.,(1995) Chlamydia pneumoniae (TWAR) Clinical Microbiology Reviews ; 4: 451-461

[21] Washington, A.E., Johnson, R..E, Sanders, L.L,(1987). Chlamydia trachomatis infections in the United States. What are they costing us? Journal of Amercian Medical Association 257:2070-2072.

[22] Washington, A.E., Johnson, R.E., Sanders, L.L., Barnes, R.C., Alexander, E.R. Incidence of Chlamydia trachomatis infections in the United States using reported Neisseria gonorrhoeae as a surrogate, 1986 ;p. 487-490. In D. Oriel, G. Ridgway, J. Schachter, et al. (ed.), Chlamydia infections.Proceedings of the Sixth International Symposium on Human Chlamydial Infections. Cambridge University Press, Cambridge, England.

[23] Krul , K.G, (1995) Closing in on Chlamydia. CAP Today, 9:1-20.

[24] Batteiger B. E., Jones, R.B,(1987).Chlamydial infections. Infectious Diseases in Clinical North America, 1:55-81.

[25] Centres for disease control and prevention recommendations for the prevention and management of Chlamydia trachomatis infections 1993; MorbidMortal. Weekly Rep. 42(No. RR-12):1-39

[26] Rietmeijer, C.A.M, Judson, F.N., van Hensbroek, M.B., Ehret, J.M., Douglas, J.M., Jr ,(1991). Unsuspected Chlamydia trachomatis infection in heterosexual men attending a sexually transmitted diseases clinic: evaluation of risk factors and screening methods. Sexually Transmitted. Disease, 18:28-35.

[27] Stamm, W.E., Koutsky, L.A., Benedetti, J.K., Jourden, J.L., Brunham, R.C., Holmes, K.K.,(1984) Chlamydia trachomatis urethral infections in men. Prevalence, risk factors, and clinical manifestations.Annals of Internal Medicine, 100:47-51.

[28] Schachter, J., Grossman, M., Sweet, R.L., Holt, J., Jordan, C., Bishop, E, (1986). Prospective study of perinatal transmission of Chlamydia trachomatis . Journal of American Medical Association, 255: 3374-3377.

[29] Thompson, S., B. Lopez, K..H., Wong, R.,(1982). A prospective study of chlamydial and mycoplasmal infections during pregnancy, p. 155-158. In P.-A. Mårdh, K. K. Holmes, J. D. Oriel, J. Schachter, and P. Piot (ed.), Chlamydial infections. Fernstrom Foundation Series. Elsevier Biomedical Press, Amsterdam, The Netherlands.

[30] Preece, P.M., Anderson, J.M., Thompson, R.G.,(1989) Chlamydia trachomatis infection in infants: a prospective study. Archives of Diseases in Children, 64: 525-529.

[31] Claesson, B. A., Trollfors, B., Brolin, I.,Granstrom, M., Henrichsen, J., Jodal, U., Juto, P., Kallings, I., Kanclerski, K., Lagergard, T,(1989), Etiology of community-acquired pneumonia in children based on antibody responses to bacterial and viral antigens. Pediatrics. Infectious Diseases. Journal,; 8:856-862.

[32] Weiss, S.G., Newcomb, R.W., Beem, M.O., (1986). Pulmonary assessment of children after Chlamydia pneumonia of infancy. Journal of Paediatrics,108: 659-664 
[33] Zelin, J.M., Robinson, A.J., Ridgway, G.L., Allason-Jones, E., .Williams, P. (1995). Chlamydial urethritis in heterosexual men attending a genitourinary medicine clinic: prevalence, symptoms, condom usage and partner change. International Journal of Sexually Transmitted Diseases AIDS 6:27-30.

[34] Wallace, D.J., Weisman, M, (2000). "Should a war criminal be rewarded with eponymous distinction? The double life of Hans Reiter (1881-1969)". Journal of Clinical Rheumatology, $6: 49-54$.

[35] Kvien ,T., Glennas, A., Melby, K., Granfors, K.(1994) "Reactive arthritis: Incidence, triggering agents and clinical presentation". Journal of Rheumatology , 21 : 115-22.

[36] Pearlman, M. D., McNeeley, S.G. (1992). A review of the microbiology immunology, and clinical implications of Chlamydia trachomatis infections. Obsteterics Gynecology Survey, $47: 448-461$

[37] Madhavan, H.N., (1999). Laboratory investigations on viral and Chlamydia trachomatis infections of the eye: Sankara Nethralaya experiences. Indian Journal of Ophthalmology. , 47:241-6

[38] Rao, S.K., Madhavan, H.N., Padmanabhan, P., Lakshmi, G.S., Natarajan, K., Garg, D, (1996) Ocular chlamydial infections. Clinicomicrobiological correlation. Cornea, 15:62-5.

[39] Madhavan, H.N., Rao, S.K., Natarajan, K., Sitalakshmi, G., Jayanthi, I., Roy, S., (1994). Evaluation of laboratory tests for diagnosis of chlamydial infections in conjunctival specimens. Indian Journal of Medical Research. 100:5-9.

[40] Claas, H.C., Melchers, W.J., de Bruijn, I.H., De Graaf, M., van Dijk ,W.C., Lindeman, J., Quint,W.G. (1990) Detection of Chlamydia trachomatis in clinical specimens by the polymerase chain reaction. European Journal of Clinical Microbiology and Infectious Diseases; $9: 864-868$

[41] Dutilh, B., Bebear, C., Rodriguez, P., Vekris, A., Bonnet, J., Garret, M,.(1989).Specific amplification of a DNA sequence common to all Chlamydia trachomatis serovars using the polymerase chain reaction. Research in. Microbiology, 140:7-16

[42] Malathi, J., Madhavan ,H.N., Therese, K.L., Rinku, J.P., Narender, K.P.. (2002) Prevalence of Chlamydia trachomatis and herpes simplex virus in males with urethritis \& females with cervicitis attending STD clinic. Indian Journal of Medical Research,116:58-63

[43] Malathi, J., Madhavan, H.N., Therese, K.L., Joseph, P.R.,(2003). A hospital based study on the prevalence of conjunctivitis due to Chlamydia trachomatis .Indian Journal of Medical Research , 117: 71-5

[44] Malathi, J., Shyamala, G., Madhavan, H.N.,(2004) Relative susceptibility of six continuous cell lines for cultivation of Chlamydia trachomatis. Indian Journal of Medical Microbiology ,22: 169-71

[45] Malathi, J., Madhavan, H.N., Therese, K.L., Shyamala, G. ,(2004) Polymerase chain reaction to detect Chlamydia trachomatis and adenovirus in the nasopharyngeal aspirates from paediatric patients with lower respiratory infections .Indian Journal of Pathology and Microbiology. 47:302-5.

[46] Malathi, J., Shyamala, G., Feeba, V., Therese, K.L., Madhavan, H.N. (2007).Optimization of a polymerase chain reaction (PCR) for increasing its sensitivity to detect 
Chlamydia pneumoniae specific genome. Indian Journal of Pathology and Microbiology 2007,50 : 104-106

[47] Andrea ,S.B., Chapin ,K.C. (2011). "Comparison of Aptima Trichomonas vaginalis Transcription-Mediated Amplification Assay and BD Affirm VPIII for Detection of T. vaginalis in Symptomatic Women: Performance Parameters and Epidemiological Implications.". Journal of Clinical Microbiology , 49: 866-9.

[48] Svensson, L.O., Mares, I., Olsson, S.E., Nordstrom, M.L. (1991).Screening for Chlamydia trachomatis infectionin women and aspects of the laboratory diagnostics. Acta Obstetrics Gynaecology Scandinavia, 70: 587-590

[49] Watson, E.J., Templeton, A., Russell, I., Paavonen, J., Mardh, P., Sracy, A., Pederson, B.S, (2002). The accuracy and efficacy of screening tests for Chlamydia trachomatis: a systematic review. Journal of Medical Microbiology,154:1021-1031

[50] Land, J.A., Van Bergen, J.E.A.M., Morne, S.A., Postma, M.J. (2010) Epidemiology of Chlamydia trachomatis infection in women and the cost effectiveness of screening. Human reproduction Update, $16: 189-204$

[51] Hahn ,D.L., McDonald, R., (1998) Can acute Chlamydia pneumoniae respiratory tract infection initiate chronic asthma. Annals of Allergy Asthma and Immunology, 81: 339344

[52] French, J. I., McGregor, J. A., Draper, D., Parker, R. \& McFee, J. (1999). Gestational bleeding, bacterial vaginosis, and common reproductive tract infections: risk for preterm birth and benefit of treatment. Obstetrics $\mathcal{E}$ Gynecology 93, 715 - 724.

[53] Gencay, M., Koskiniemi, M., Saikku, P., Puolakkainen, M., Raivio, K., Koskela, P. \& Vaheri, A. (1995). Chlamydia trachomatis seropositivity during pregnancy is associated with perinatal complications. Clinical Infectious Diseases 21, 424 - 426.

[54] US Preventive Services Task Force. Screening for chlamydial infection: U.S. Preventive Services Task Force recommendation statement.(2007) Annals of Internal Medicine,147:128--34

[55] Grayston, J. T., Kuo, C.C., Wang, S.P. Altman J.,(1986).A new Chlamydia psittaci strain called TWAR from acute respiratory infections. New England. Journal of Medicine, 315:161-168.

[56] World Health Organization (WHO) Report on the prevention of Chlamydia trachomatis infection 2004

[57] Carlson, J.H,, Hughes, S., Hogan, D., Cieplak, G., Sturdevant, D.E., McClarty, G., Caldwell, H.D., Belland, R.J,(2004) Polymorphisms in Chlamydia trachomatis cytotoxin locus associated with ocular and genital isolates Infection and Immunity, 72: 7063-7072

[58] Lulter, E.I., Bonner, C., Holland ,M.T., Suchland, R., Stamm, W.E., Jewett, T.J., McClarty, G., Hackstadt, T,(2010). Phylogenetic analysis of Chlamydia trachomatis Tarp and correlation with clinical phenotype. Infection and Immunity , 78: 3678-3688

[59] McCoy, A.J., Adams, N.E., Hudson, A.O, Gilvarg, C., Leustek, T., Maurelli, A.T. (2006). "L,L-diaminopimelate aminotransferase, a trans-kingdom enzyme shared by Chlamydia and plants for synthesis of diaminopimelate/lysine". Proceedings of . National. Academy and Sciences. U.S.A. ,103 : 17909-14. 
[60] Borel ,N., Casson, N., Entenza, J.M., Kaiser, C., Pospischil, A., Greub, G. (2009).Tissue microarray and immunohistochemistry as tools for evaluation of antibodies against Chlamydia like bacteria Journal of Medical Microbiology, 58: 863-866 


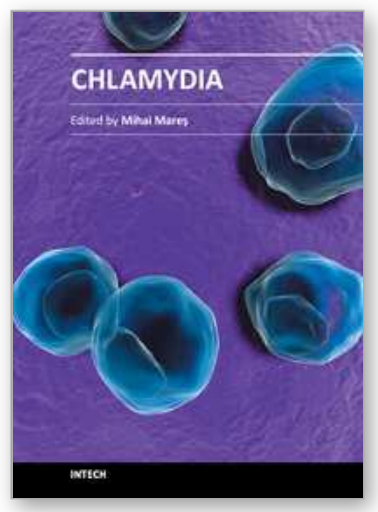

\author{
Chlamydia \\ Edited by Prof. Mihai Mares
}

ISBN 978-953-51-0470-4

Hard cover, 358 pages

Publisher Intech

Published online 30, March, 2012

Published in print edition March, 2012

Nowadays, Chlamydia still represents a redoubtable pathogen. Among its consequences, the blindness in children and severe impairment of reproductive health in adults are the most mutilating. Worldwide, it is estimated that six million of people suffer from post-trachoma blindness and almost 90 million become sexually infected each year. Due to its silent evolution and sexually transmission, the chlamydial infection can occur in anyone. The book "Chlamydia - A Multifaceted Pathogen" contains an updated review of all-important issues concerning the chlamydial infection. It comprises 18 chapters grouped in four major parts dealing with etiology and pathogenicity, clinical aspects, diagnosis and prevention. The new molecular data about the pathogenicity and the exhaustive presentation of clinical findings bring novelty to the book and improve our knowledge about Chlamydia induced diseases.

\title{
How to reference
}

In order to correctly reference this scholarly work, feel free to copy and paste the following:

H.N. Madhavan, J. Malathi and R. Bagyalakshmi (2012). Insights into the Biology, Infections and Laboratory Diagnosis of Chlamydia, Chlamydia, Prof. Mihai Mares (Ed.), ISBN: 978-953-51-0470-4, InTech, Available from: http://www.intechopen.com/books/chlamydia/insights-into-the-biology-infections-and-laboratorydiagnosis-of-chlamydia

\section{INTECH}

open science | open minds

\author{
InTech Europe \\ University Campus STeP Ri \\ Slavka Krautzeka 83/A \\ 51000 Rijeka, Croatia \\ Phone: +385 (51) 770447 \\ Fax: +385 (51) 686166 \\ www.intechopen.com
}

\author{
InTech China \\ Unit 405, Office Block, Hotel Equatorial Shanghai \\ No.65, Yan An Road (West), Shanghai, 200040, China \\ 中国上海市延安西路65号上海国际贵都大饭店办公楼 405 单元 \\ Phone: +86-21-62489820 \\ Fax: $+86-21-62489821$
}


(C) 2012 The Author(s). Licensee IntechOpen. This is an open access article distributed under the terms of the Creative Commons Attribution 3.0 License, which permits unrestricted use, distribution, and reproduction in any medium, provided the original work is properly cited. 